\title{
RESEARCH
}

Open Access

\section{LncRNA HOTAIR-mediated MTHFR methylation inhibits 5-fluorouracil sensitivity in esophageal cancer cells}

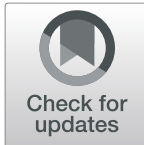

Shuyao Zhang ${ }^{1,2+}$, Fuchun Zheng ${ }^{3 \dagger}$, Liqun Zhang ${ }^{4 \dagger}$, Zuojun Huang $^{2 \dagger}$, Xiaoshan Huang $^{2}$, Zhen Pan ${ }^{2}$, Shuang Chen ${ }^{1,2}$, Chenchen Xu' ${ }^{1}$ Yi Jiang ${ }^{5}$, Shuyi Gu${ }^{2}$, Chengkuan Zhao ${ }^{1}$, Qiuzhen Zhang ${ }^{1}$ and Ganggang Shi ${ }^{*}$

\begin{abstract}
Background: Esophageal cancer (EC) represents one of the most aggressive digestive neoplasms globally, with marked geographical variations in morbidity and mortality. Chemoprevention is a promising approach for cancer therapy, while acquired chemoresistance is a major obstacle impeding the success of 5-fluorouracil (5-FU)-based chemotherapy in EC, with the mechanisms underlying resistance not well-understood. In the present study, we focus on exploring the role of long non-coding RNA (IncRNA) HOTAIR in EC progression and sensitivity of EC cells to 5 -FU.
\end{abstract}

Methods: Paired cancerous and pre-cancerous tissues surgically resected from EC patients were collected in this study. Promoter methylation of the MTHFR was assessed by methylation-specific PCR. RIP and ChIP assays were adopted to examine the interaction of DNA methyltransferases (DNMTs) with IncRNA HOTAIR and MTHFR, respectively. EC cells resistant to 5-FU were induced by step-wise continuous increasing concentrations of 5-FU. The sensitivity of EC cells to 5-FU in vivo was evaluated in nude mice treated with xenografts of EC cells followed by injection with 5-FU (i.p.).

Results: We found reciprocal expression patterns of IncRNA HOTAIR and MTHFR in EC tissues and human EC cells. Interference with IncRNA HOTAIR enhanced 5-FU-induced apoptosis, exhibited anti-proliferative activity, and reduced promoter methylation of the MTHFR in EC cells. Besides, overexpression of MTHFR attenuated the acquired chemoresistance induced by overexpression of IncRNA HOTAIR in EC cells. At last, enhanced chemosensitivity was observed in vivo once nude mice xenografted with IncRNA HOTAIR-depleted EC cells.

Conclusion: Together, our study proposes that pharmacologic targeting of IncRNA HOTAIR sensitizes EC cells to 5FU-based chemotherapy by attenuating the promoter hypermethylation of the MTHFR in EC.

Keywords: Esophageal cancer, IncRNA HOTAIR, MTHFR, 5-fluorouracil, Chemosensitivity

\footnotetext{
* Correspondence: ggshi@stu.edu.cn

†Shuyao Zhang, Fuchun Zheng, Liqun Zhang and Zuojun Huang contributed equally to this work.

'Department of Pharmacology, Shantou University Medical College, Shantou

515041, P.R. China

Full list of author information is available at the end of the article
}

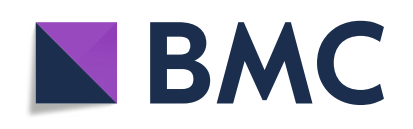

(- The Author(s). 2020 Open Access This article is licensed under a Creative Commons Attribution 4.0 International License, which permits use, sharing, adaptation, distribution and reproduction in any medium or format, as long as you give appropriate credit to the original author(s) and the source, provide a link to the Creative Commons licence, and indicate if changes were made. The images or other third party material in this article are included in the article's Creative Commons licence, unless indicated otherwise in a credit line to the material. If material is not included in the article's Creative Commons licence and your intended use is not permitted by statutory regulation or exceeds the permitted use, you will need to obtain permission directly from the copyright holder. To view a copy of this licence, visit http://creativecommons.org/licenses/by/4.0/. The Creative Commons Public Domain Dedication waiver (http://creativecommons.org/publicdomain/zero/1.0/) applies to the data made available in this article, unless otherwise stated in a credit line to the data. 


\section{Background}

Esophageal cancer (EC) ranks as the eighth most prevalent cancer globally [1]. Multiple risk factors are reported to contribute its occurrence and development, including cigarette smoking, alcohol consumption, obesity, and low fruit/vegetable intake [2]. Currently, standard treatment modalities for patients with EC include surgery, radiation therapy, and chemotherapy [3]. Despite substantial advances in diagnosis and treatment, EC has overall poor prognosis, with overall 5 -year survival rates ranging between 15 and 25\% [4]. 5-fluorouracil (5-FU) is widely considered to be the most effective chemotherapeutic agent for treatment for EC [5]. However, esophageal tumors frequently develop resistance to 5-FU, especially in recurrence cases [6]. Therefore, there is a need to identify novel molecular targets that can facilitate the promotion of chemosensitivity of EC cells to 5-FU.

LncRNAs are a group of non-protein-coding transcripts with nucleotides lengths of 200 or more and are reported as dysregulated in tumor initiation and progression, including EC [7]. LncRNA HOX transcript antisense RNA (HOTAIR), an inhibitor of the HOXD genes, is secreted from the HOXC locus [8]. LncRNA HOTAIR, a typical IncRNA, has been implicated in the development of esophageal squamous cell carcinoma (ESCC) [9]. In particular, HOTAIR is understood to be capable of regulating cell invasiveness, migration, and apoptosis in ESCC, and thus has been proposed as a novel biomarker relevant to its diagnosis and prognosis [10]. Notably, Yan et al. have suggested that upregulation of HOTAIR is associated with chemoresistance [11]. Previous studies have revealed that alterations in DNA methylation are innate to various human cancers, including EC [12, 13]. HOTAIR is known to regulate gene expression through epigenetic modifications, including DNA methylation [14].

In addition, methylenetetrahydrofolate reductase (MTHFR), involved in 5-methyltetrahydrofolate synthesis and homocysteine remethylation, may affect the occurrence and development of cancer by directly regulating DNA methylation [15]. The role of MTHFR in EC has also been demonstrated [16]. Notably, MTHFR has been shown to affect 5-FU based chemotherapy in colorectal cancer [17]. However, the role of IncRNA HOTAIR-mediated methylation of the MTHFR promoter in the chemosensitivity of EC cells to 5-FU remains largely enigmatic. Thus, the aim of the present study was to investigate the possible effects of IncRNA HOTAIR on the chemosensitivity of EC cells to 5-FU via a potential regulation of MTHFR methylation.

\section{Methods}

\section{Ethics statement}

The study protocol was approved by the Ethics Committee of the Cancer Hospital of Shantou University
Medical College. Written informed consent was obtained from all patients prior to enrollment. All animal experiments were conducted in accordance with the Guide for the Care and Use of Laboratory Animal by International Committees. Every effort was made to minimize the numbers and suffering of the included animals.

\section{Study subjects}

A total of 70 EC tissue samples and adjacent normal tissues were collected from patients ( 43 patients $<50$ years old and 27 patients $\geq 50$ years old) diagnosed with nonspecific invasive EC at the Cancer Hospital of Shantou University Medical College from April 2017 to March 2019. All included EC tissues were diagnosed pathologically as ESCC. Morphological observations and diagnosis of all cases were made by more than two deputy pathologists according to World Health Organization (WHO) classification criteria [18]. There were 47 cases with EC at grade I + II and 23 cases with EC at grade III. Tumor staging was conducted according to American Joint Committee on Cancer (AJCC) 8th Edition TNM Staging Form [19]. The patients were classified into the TNM stage of I + II (58) and the TNM stage of IIIa (12). All patients showed no lymph node metastasis (LNM), and received neither radiotherapy nor chemotherapy prior to surgery.

\section{Preparation of 5-FU resistant EC cell lines}

Cell lines in this study were tested for mycoplasma contamination prior to experiments. The EC cell lines KYSE150, EC109, and TE-1 and human normal esophageal epithelial cell line HEEC were purchased from American Type Culture Collection (ATCC) (VA, USA). All cell lines were added with RPMI 1640 medium (Santa Cruz Biotechnology, Inc., Santa Cruz, CA, USA) supplemented with $10 \% \mathrm{FBS}$ and $100 \mathrm{U} / \mathrm{mL}$ penicillin -streptomycin and cultured in a $5 \% \mathrm{CO}_{2}$ incubator at $37^{\circ} \mathrm{C}$. Next, the concentration gradient method was used to construct 5-FU resistant EC cell lines (TE-1/5-FU) for three times, where 5-FU concentrations used were from 1 to $20 \mu \mathrm{g} / \mathrm{mL}$, respectively. After transduction for 190 days, the concentration $5 \mu \mathrm{g} / \mathrm{mL}$ of 5 -FU that could stabilize the drug resistance of TE-1 cells was selected for subsequent analysis.

\section{Cell grouping and treatment}

TE-1/5-FU cells $\left(4 \times 10^{5}\right.$ cells/well $)$ were inoculated in 6well plates. Expression vectors containing the lncRNA HOTAIR or MTHFR, two shRNAs against lncRNA HOTAIR, and their respective negative controls (empty vector, scramble shRNA) were obtained from Shanghai Sangon Biotechnology Co. Ltd. (Shanghai, China) and delivered into TE-1/5-FU cells using the lipofectamin 
2000 kit according to manufactures' instructions. 5-Aza$\mathrm{CdR}$ was used to inhibit DNA methylation in cells.

\section{RNA isolation and quantification}

Total RNA was extracted from tissues and cells using RNeasy Mini Kit (Qiagen Company, Hilden, Germany). The total RNA was reverse transcribed into cDNA using a PrimeScript RT kit (TaKaRa Biotechnology Co. Ltd., Dalian, China) according to the manufacturer's protocol. Primer sequences of lncRNA HOTAIR, MTHFR-U, and MTHFR-M (Table 1) were designed and then synthesized by TaKaRa Biotechnology Co. Ltd. (Dalian, China). The ABI7500 quantitative PCR instrument (7500, ABI Company, Oyster Bay, NY, USA) was employed to conduct reverse transcription quantitative polymerase chain reaction (RT-qPCR). The $2^{-\Delta \Delta C t}$ method was used to calculate the relative mRNA expression levels of the target genes.

\section{Western blot analysis}

TE-1 cells or tissue samples were lysed with radio immunoprecipitation assay (RIPA) peptide lysis buffer (BB3209, Shanghai BestBio Co., Ltd., Shanghai, China) to extract the total protein. The proteins were separated with sodium dodecyl sulfate-polyacrylamide gel electrophoresis (SDS-PAGE) for $1 \mathrm{~h}$ and then transferred onto a polyvinylidene fluoride (PVDF) membrane. The membrane was incubated with rabbit anti-human primary antibody MTHFR (1: 1000, ab203785, Abcam Inc., Cambridge, MA, USA) at $4{ }^{\circ} \mathrm{C}$ overnight with GAPDH (1: 500, ab8245, Abcam Inc., Cambridge, MA, USA) used as the internal reference gene. Next, the membrane was incubated with horseradish peroxidase (HRP)-labeled goat anti-rabbit immunoglobulin G (IgG) (1: 20000; ab205718, Abcam Inc., Cambridge, MA, USA). Protein blots were visualized by ECL-associated fluorography (Merck Millipore, Billerica, MA, USA).

\section{Dual luciferase reporter gene assay}

The MTHFR dual luciferase reporter gene vector and mutants with lncRNA HOTAIR binding site mutation

Table 1 Primer sequences for RT-qPCR

\begin{tabular}{lll}
\hline Genes & & Sequences (5'-3') \\
\hline InCRNA HOTAIR & $F$ & GGAAAGATCCAAATGGGACCA \\
MTHFR-U & $R$ & CTAGGAATCAGCACGAAGCAAA \\
MTHFR-M & $F$ & GGCTGACCTGAAGCACTTGAA \\
& $R$ & AGAAAAGCTGCGTGATGATGAA \\
GAPDH & $F$ & TGAAGGAGAAGGTGTCTGCGGGA \\
& $R$ & AGGACGGTGCGGTGAGATG \\
& F & AGAAGGCTGGGGCTCATTTG \\
\hline
\end{tabular}

$F$ forward, $R$ reverse
(MTHFR-WT and MTHFR-MUT) were each constructed. These two reporter plasmids were cotransfected into cells that overexpressed lncRNA HOTAIR and NC plasmids. The Dual-Luciferase Reporter Assay System from Genecopoeia (D0010, Beijing Solarbio Science \& Technology Co. Ltd., Beijing, China) was employed to detect the luciferase activity of MTHFR promoter region induced by IncRNA HOTAIR in EC cells. The fluorescence intensity was measured using the GLomax20/20 Luminometer (Promega Corporation, Madison, WI, USA).

\section{RNA-fluorescence in situ hybridization (FISH) assay}

The website http://lncatlas.crg.eu/ was employed to predict the localization of IncRNA HOTAIR in TE-1 EC cells, which was identified using a FISH kit (Roche Diagnostics $\mathrm{GmbH}$, Mannheim, Germany). The cells were incubated with a digoxin-labeled lncRNA HOTAIR probe (Sigma, St. Louis (MO, USA), followed by staining with 4', 6-diamidino-2-phenylindole (DAPI) (Sigma, St. Louis, MO, USA). Then, the cells were washed with cold PBS and photographed using a confocal laser scanning microscope (FV1000, Olympus, Tokyo, Japan).

\section{RNA-binding protein immunoprecipitation (RIP) assay}

Cell lysates were incubated with protein-G agarose beads pre-coated with anti-DNMT1 (ab13537, Abcam, Cambridge, UK), anti-DNMT3a (, ab2850, Abcam, Cambridge, UK), anti-DNMT3b (ab2851, Abcam, Cambridge, UK) or normal rabbit IgG. The resultant complexes were then incubated with $150 \mu \mathrm{L}$ proteinase $\mathrm{K}$ buffer to extract protein. Total RNA was extracted using the TRIZOL method and used for RT-qPCR.

\section{Methylation-specific PCR (MSP) assay}

Frozen EC tissues and adjacent normal tissues were obtained. DNA was extracted using the ammoniachloroform extraction method and modified with sodium bisulfite. The modified DNA was purified using a DNA Purification Kit (Promega, Madison, WI, USA), and amplified with bisulfite-modified DNA as a template. Primers for MTHFR MSP-M and MTHFR MSP-U were synthesized by Shanghai Sangon Biotechnology Co. Ltd. (Shanghai, China). The PCR reaction conditions were 35 cycles of pre-denaturation at $95^{\circ} \mathrm{C}$ for $10 \mathrm{~min}$, denaturation at $94^{\circ} \mathrm{C}$ for $1 \mathrm{~min}$, annealing at $60^{\circ} \mathrm{C}$ for $50 \mathrm{~s}$, and extension at $72{ }^{\circ} \mathrm{C}$ for $10 \mathrm{~min}$. The MSP results were determined as described in a previous study [20].

\section{Chromatin immunoprecipitation (ChIP) assay}

A ChIP kit (Merck Millipore, Billerica, MA, USA) was used to detect the enrichment of DNMT1, DNMT3a, and DNMT3b within the MTHFR promoter region. TE1 cells were treated with formaldehyde for $10 \mathrm{~min}$ to 
generate DNA-protein cross-links. Cell lysates were sonicated to generate chromatin fragments of $200-300 \mathrm{bp}$ and immunoprecipitated with DNMT1 (ab13537, Abcam, Cambridge, UK), DNMT3a (ab2850, Abcam, Cambridge, UK), DNMT3b (ab2851, Abcam, Cambridge, UK), IgG as a negative control, or RNA polymerase ii antibody as a positive control. The Protein Agarose/ Sepharose was used to precipitate the endogenous DNA-protein complexes, followed by de-crosslinking at $65^{\circ} \mathrm{C}$ overnight. MTHFR promoter-specific primer sequences (Table 1) were used for detecting the binding of DNMT1, DNMT3a, and DNMT3b with the MTHFR promoter region.

\section{5-ethynyl-2'-deoxyuridine (EdU) labeling assay}

EC cells were seeded into 96-well plates $\left(1.6 \times 10^{5}\right.$ cells/well), and experimental procedures were conducted according to the instructions of EdU kit (C10310, Guangzhou RiboBio Co., Ltd., Guangdong, China). Briefly, each well was added with $50 \mu \mathrm{M}$ EdU $(100 \mu \mathrm{L})$ at $37^{\circ} \mathrm{C}$ for $4 \mathrm{~h}$, followed by fixation in $4 \%$ formaldehyde at room temperature for $15 \mathrm{~min}$. Next, the cells were treated with $0.2 \%$ Triton $\mathrm{X}-100$ at room temperature for $5 \mathrm{~min}$ and $100 \mu \mathrm{L}$ Apollo ${ }^{\circ}$ mixture (C10338-2, Guangzhou RiboBio Co., Ltd., Guangdong, China) for $30 \mathrm{~min}$, and then cultured with $100 \mu \mathrm{L}$ Hoechst33342 (Guangzhou RiboBio Co., Ltd., Guangdong, China). DAPI was added for $30 \mathrm{~min}$ in order to label the cell nuclei. Cells were observed and imaged using a fluorescence microscope (Olympus, Tokyo, Japan). The Image-Pro Plus (IPP) 6.0 software (Media Cybernetics, Bethesda, MD, USA) was utilized to count the EdU-positive cells (red).

\section{Cell counting kit-8 (CCK-8) assay}

When cell confluence reached about $80 \%$, the cells were washed with PBS twice, and trypsinized (at $0.25 \%$ ) to prepare a single cell suspension. After counting, these cells were inoculated into 96-well plates $\left(3 \times 10^{3} \sim 6 \times\right.$ $10^{3}$ cells/well) at $200 \mu \mathrm{L}$ of suspension per well. Six wells were used as replicates of each condition. After incubation for $24 \mathrm{~h}, 48 \mathrm{~h}$, and $72 \mathrm{~h}$, samples were removed and incubated with $10 \mu \mathrm{L}$ CCK-8 (VP757, DOJINDO, Kumamoto, Kyushu, Japan) for $2 \mathrm{~h}$. The optical density (OD) value was measured at a wavelength of $450 \mathrm{~nm}$ using a microplate reader (BIOBASE-EL10A, Jinan Boxin Biotechnology Co., Ltd., Jinan, China). The cell viability curve was plotted with time-duration of incubation on the $\mathrm{X}$-axis and $\mathrm{OD}$ value on the $\mathrm{Y}$-axis. All experiments were repeated three times and the $\mathrm{IC}_{50}$ value was determined, which referred to the drug concentration required for cell survival. The $\mathrm{IC}_{50}$ value was calculated by the least square method using FORECAST function in EXCEL software.

\section{Flow cytometry}

Propidium (PI) staining was adopted to assess the cell cycle of EC cells. Briefly, $48 \mathrm{~h}$ after transfection, cells were washed 3 times with cold PBS, centrifuged, and the supernatant was discarded. The cell concentration was adjusted to approximately $1 \times 10^{5}$ cells $/ \mathrm{mL}$ after cells were resuspended in $\mathrm{PBS}$, and added with $1 \mathrm{~mL}$ of precooled $75 \%$ ethanol $\left(-20^{\circ} \mathrm{C}\right)$ to fix cells at $4{ }^{\circ} \mathrm{C}$ for $1 \mathrm{~h}$, followed by centrifugation. The ice ethanol and the supernatant were discarded, and cells were added with $100 \mu \mathrm{L}$ of RNase A in the dark, water bathed for $30 \mathrm{~min}$ $37^{\circ} \mathrm{C}$, and then added with $400 \mu \mathrm{L}$ of PI (Sigma). The cells were then incubated in dark conditions at $4{ }^{\circ} \mathrm{C}$ for $30 \mathrm{~min}$, and the cell cycle was determined using flow cytometry at $488 \mathrm{~nm}$.

The apoptosis of EC cells was detected using an Annexin V-fluorescein isothiocyanate (FITC)/PI double staining kit $(556,547$, SHANGHAI SOLJA TECHNOLOGY CO., LTD., Shanghai, China). In brief, the cell suspension was incubated with $5 \mu \mathrm{L}$ Annexin V-FITC for $15 \mathrm{~min}$, followed by incubation with $5 \mu \mathrm{L}$ PI for $5 \mathrm{~min}$. FITC was detected at wavelengths of $480 \mathrm{~nm}$ and 530 $\mathrm{nm}$ and PI was detected at a wavelength of more than $575 \mathrm{~nm}$ using a flow cytometer (Cube6, Partec, Inc., IL, USA).

\section{Tumor xenografts in nude mice}

A total of 48 nude mice of specific pathogen free (SPF) grade (aging 4 weeks and weighing 14-16g) were obtained from the Medical Discovery Leader Co., Ltd. (Beijing China). A total of $2 \times 10^{6}$ cells were mixed with $50 \mu \mathrm{L}$ Matrigel Matrix (1: 1) and inoculated subcutaneously into the armpit of the nude mice. After 28 days, anesthesia was induced, and the nude mice were euthanized using 3\% Sodium pentobarbital $(1 \mathrm{ml} / 100 \mathrm{~g}$, P3761, Sigma-Aldrich Chemical Company, St Louis, MO, USA), and the tumor tissues were obtained for further analysis.

\section{Immunohistochemistry}

The expression of MTHFR was detected using peroxidase-labeled streptavidin peroxidase (SP). The paraffin samples of mouse tissues were sectioned in a continuous manner into $5 \mu \mathrm{m}$ sections. After routine dehydration, immunohistochemistry was carried out according to routine protocol. Briefly, after treatment with $3 \%$ hydrogen peroxide at room temperature for $10 \mathrm{~min}$ to block endogenous peroxidase, normal non-immune animal serum was added for $10 \mathrm{~min}$. The sections were treated with primary antibody rabbit anti human MTHFR (ab203785, 1: 1000, Abcam, Cambridge, UK), followed by overnight incubation at $4{ }^{\circ} \mathrm{C}$, added with 1: 500 diluted secondary antibody (goat anti rabbit IgG) labeled with biotin, incubated at $37^{\circ} \mathrm{C}$ for $20 \mathrm{~min}$, and added with $50 \mu \mathrm{l}$ 
streptavidin-peroxidase solution, followed by incubation at room temperature for $10 \mathrm{~min}$. The sections were visualized with diaminobesidine for 5-10 min and counterstained with hematoxylin, followed by dehydration, permeabilization, and mounting. The sections were observed under a microscope, and PBS served as NC.

\section{Statistical analysis}

All data was analyzed using SPSS 22.0 software (IBM Corp., Armonk, NY, USA). The measurement data was expressed as mean \pm standard deviation of three independent tests. The independent sample $t$-test was used to compare measurement data between two groups including gene expression between EC tissues and adjacent normal tissues. Comparison among multiple groups was conducted using one-way analysis of variance (ANOVA), followed by Tukey's post hoc test. Repeated measures ANOVA was used to compare tumor volume among groups, followed by Tukey's post hoc test. $p$ value $<0.05$ was indicative of statistical significance.

\section{Results}

Web-available microarray analysis indicated involvement of HOTAIR and MTHFR in EC

The EC-related gene expression dataset GSE100942 was used to predict HOTAIR expression in EC. Results showed that HOTAIR was highly expressed in EC (Fig. 1a), which was consistent with previous reports. EC-related data in the TCGA database was analyzed using 'Ualcan' database, and the resultant survival curve showed that HOTAIR expression was significantly correlated with survival in EC $(p<0.05)$ (Fig. 1b). MTHFR expression data were obtained from another EC-related gene expression dataset GSE100942, which showed that MTHFR was poorly expressed in EC (Fig. 1c). The coexpression analysis of IncRNA HOTAIR and MTHFR gene by MEM showed highly significant co-expression $(p<0.001)$ (Fig. 1d).

\section{LncRNA HOTAIR was upregulated in EC tissues and cells}

The TCGA database revealed that HOTAIR was highly expressed in EC (Fig. 2a). The EC tissues and adjacent normal tissues from 70 patients were used to determine HOTAIR expression using RT-qPCR, which was correspondingly found to be significantly higher in EC tissues than in adjacent normal tissues $(p<0.05)$ (Fig. 2b). Furthermore, RT-qPCR displayed increased HOTAIR expression in EC cell lines EC109, KYSE150, and TE-1 in comparison to HEEC cells $(p<0.05)$ (Fig. 2c). The website 'Lncatlas' predicted that IncRNA HOTAIR was located in the nucleus (Fig. 2d), which was further verified using FISH (Fig. 2e). These results indicated that

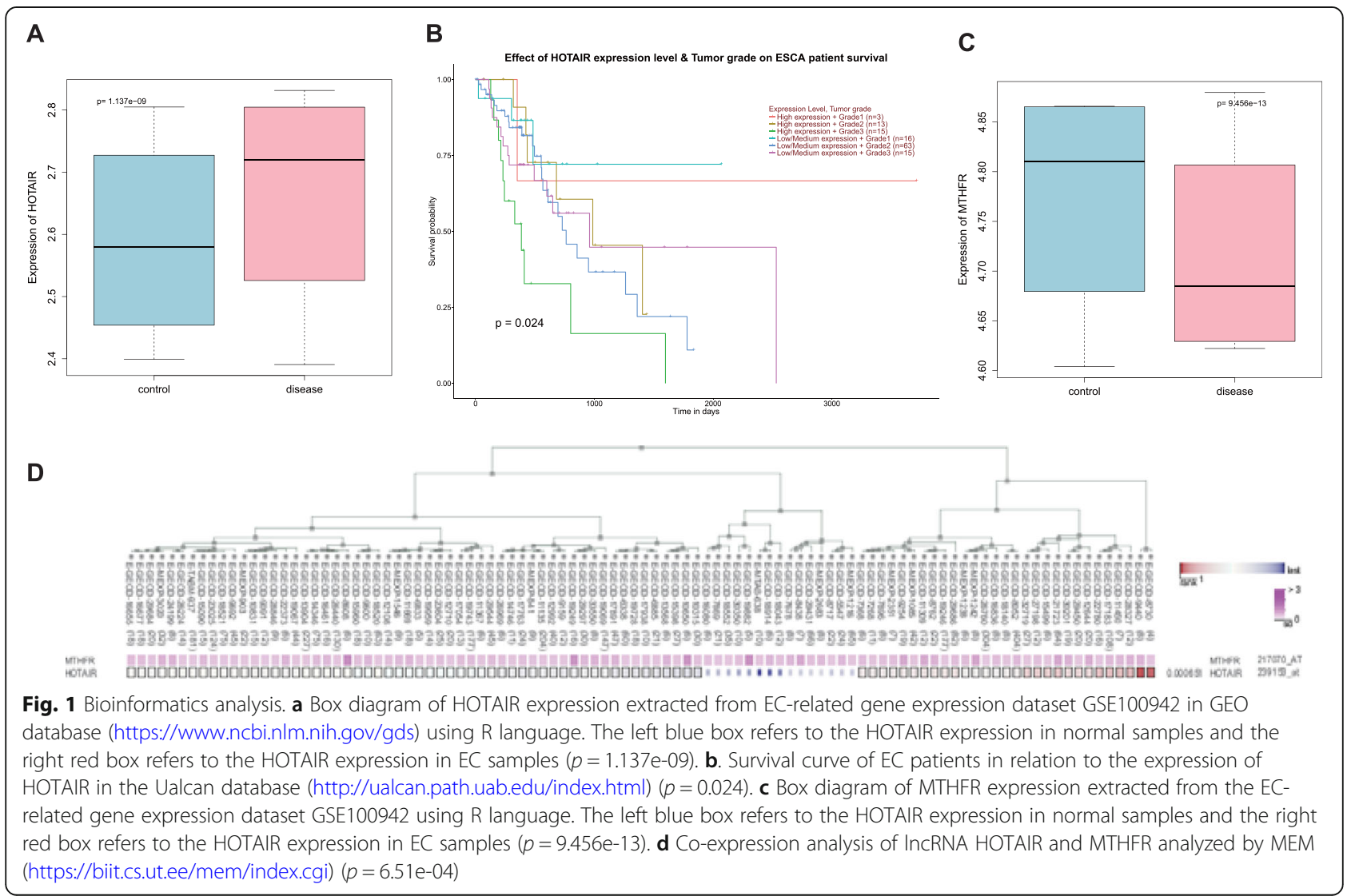




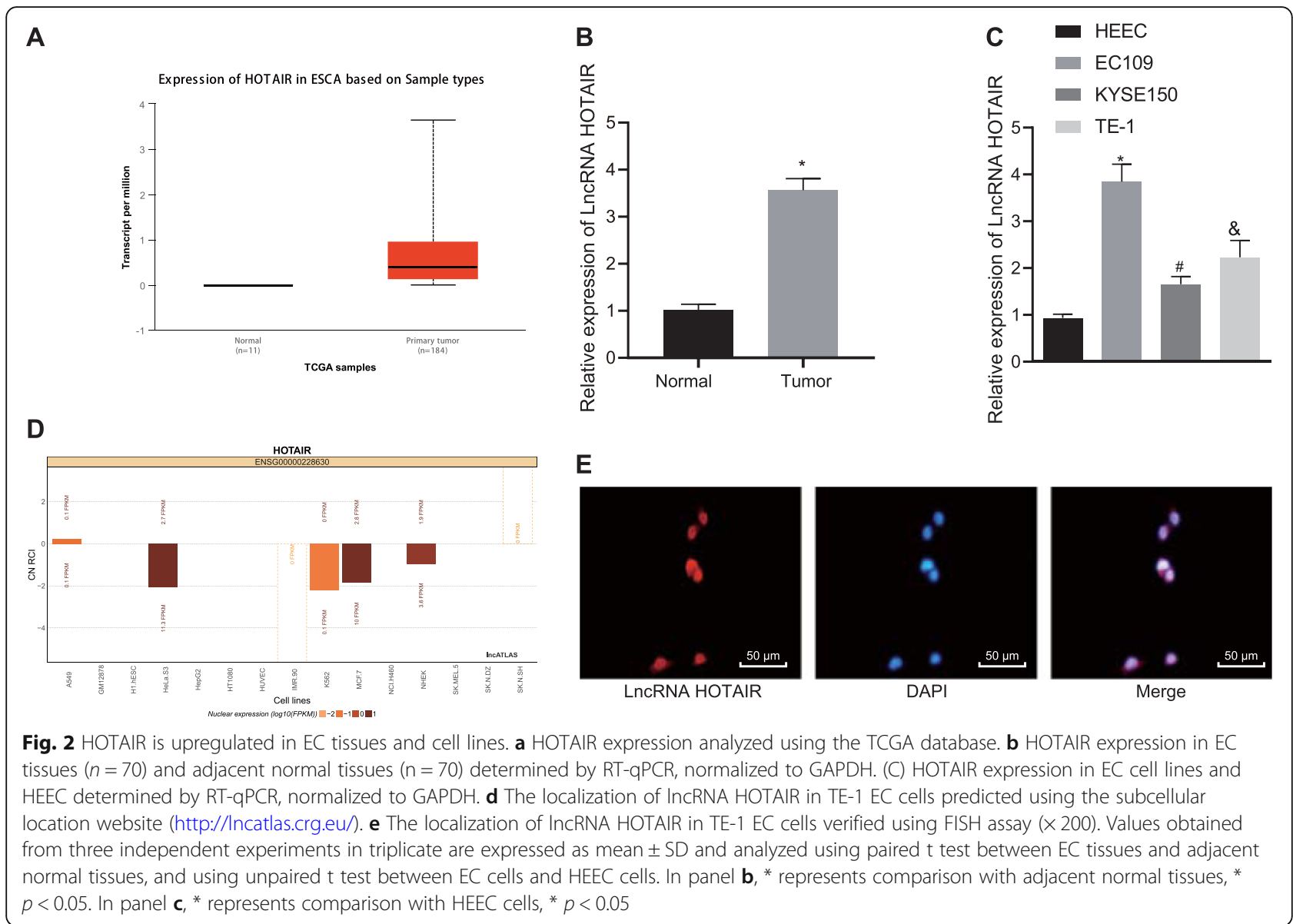

HOTAIR expression was elevated in EC tissues and cells and it was mainly located in the nucleus.

\section{Silencing of HOTAIR promoted chemosensitivity to 5-FU} In order to study the effect of IncRNA HOTAIR on drug-resistant cell lines, we used CCK- 8 assay to test the sensitivity of cell lines to 5-FU, which showed that compared with KYSE150 and EC109 cell lines, the TE-1 cell line was the most resistant to 5 -FU $(p<0.05)$ (Fig. 3a). Thus, TE-1 cells were selected to construct TE-1/5-FU resistant strain. 5-FU at higher concentration (from $1 \mu \mathrm{g} / \mathrm{mL}$ to $20 \mu \mathrm{g} / \mathrm{mL}$ ) gradually decreased the cell surviving rate (Fig. $3 \mathrm{~b}$ ). We further used CCK- 8 assay to compare the surviving rate of TE-1 cell line and TE-1/5FU cell line at a 5 -FU concentration of $5 \mu \mathrm{g} / \mathrm{mL}$, and found that the surviving rate of TE-1/5-FU cell line was significantly increased relative to that of TE-1 cell line $(p<0.05) \quad$ (Fig. 3c). To identify the relationship of IncRNA HOTAIR to drug resistance in EC, we determined HOTAIR expression in the TE- 1 cell line and in the TE-1/5-FU cell line. HOTAIR exhibited significantly higher expression in the TE-1/5-FU cell line $(p<0.05)$ (Fig. 3d). Next, TE-1/5-FU cells were treated with oeNC, sh-NC, oe-lncRNA HOTAIR, sh1-lncRNA
HOTAIR, and sh2-lncRNA HOTAIR plasmids to determine the effects of knockdown or overexpression of lncRNA HOTAIR on chemosensitivity. The findings revealed that as compared with the TE-1/5-FU cells treated with sh-NC plasmids (Fig. 3e), HOTAIR expression was decreased in TE-1/5-FU cells treated with sh1lncRNA HOTAIR and sh2-lncRNA HOTAIR plasmids, with a more pronounced decline upon treatment with sh1-lncRNA HOTAIR $(p<0.05)$. Thus, TE-1/5-FU cells treated with sh1-lncRNA HOTAIR were selected for further experiments. HOTAIR expression was increased in TE-1/5-FU cells treated with overexpressed lncRNA HOTAIR. In addition, CCK- 8 assay displayed that the depletion of IncRNA HOTAIR inhibited cell viability $(p<0.05)$ (Fig. 3f) and reduced $\mathrm{IC}_{50}$, which suggested that depletion of lncRNA HOTAIR promoted sensitivity and inhibited the chemoresistance of TE-1/5-FU cells to 5 -FU $(p<0.05)$ (Fig. 3g). EdU assay and flow cytometry showed that silencing of IncRNA HOTAIR suppressed TE-1/5-FU cell proliferation and enhanced apoptosis $(p<0.05)$ (Fig. $3 \mathrm{~h}, \mathrm{i})$, while restored IncRNA HOTAIR exerted the opposite effects. Next, we adopted PI staining using flow cytometry to verify the cell cycle of EC cells, which identified more cells at the G0/G1 phase but 


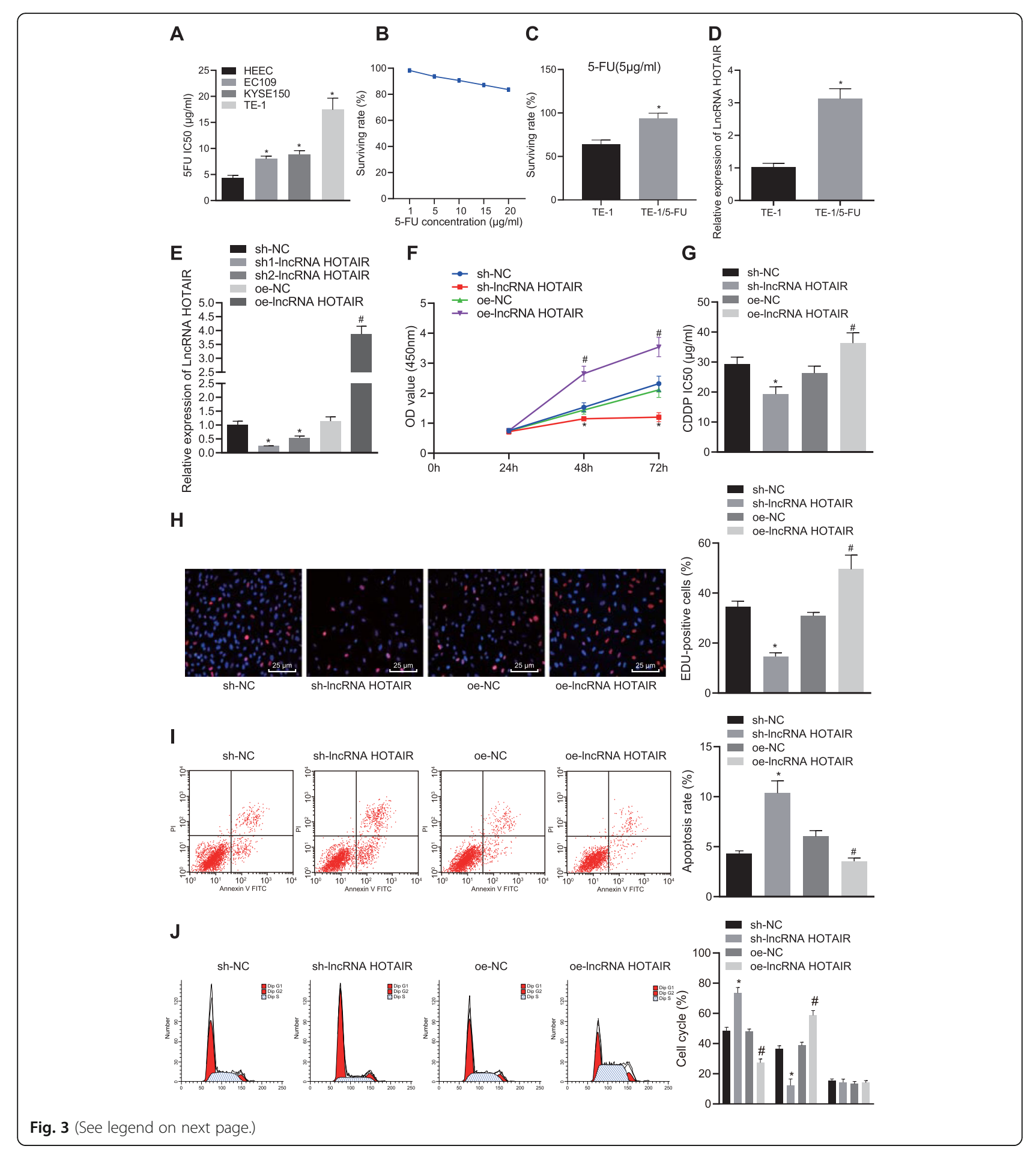




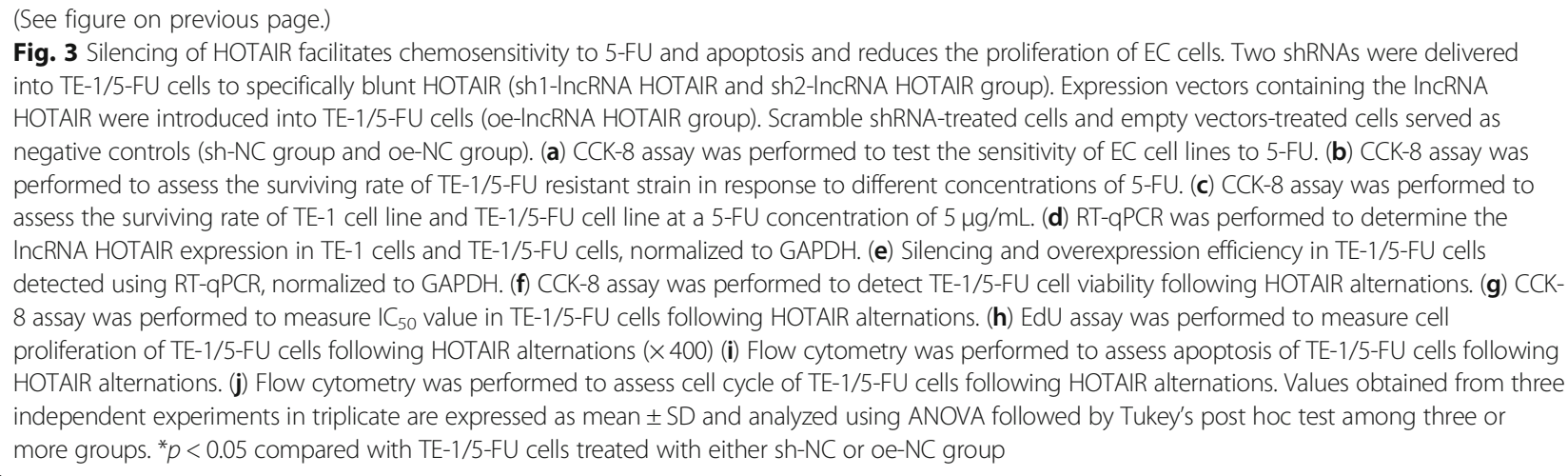

fewer cells in the $\mathrm{S}$ phase upon silencing lncRNA HOTAIR, whereas an opposite trend was observed in response to lncRNA HOTAIR overexpression $(p<0.05)$ (Fig. 3j). Thus, the findings implied that downregulation of HOTAIR promoted chemosensitivity to 5-FU and apoptosis and suppressed the proliferation of EC cells.

\section{HOTAIR promoted DNA methylation of MTHFR promoter}

In order to further study downstream regulatory mechanisms of lncRNA HOTAIR, RT-qPCR was adopted, which displayed that the MTHFR mRNA level was lower in EC tissues than that in adjacent normal tissues $(p<$ 0.05) (Fig. 4a). MethPrimer software was utilized to predict the $4200 \mathrm{bp}$ nucleotide sequence of the MTHFR promoter region and to analyze the CpG islands in its promoter region. The results confirmed that there were CpG islands in the promoter region of the MTHFR gene (Fig. 4b), indicating that MTHFR expression was reduced owing to methylation of its promoter region. In order to prove whether methylation occurred in the promoter region of the MTHFR gene in EC tissues, we detected the methylation level of CpG islands in the promoter region of MTHFR gene in $70 \mathrm{EC}$ tissues and adjacent normal tissues using MSP. The results demonstrated that the methylation level of MTHFR promoter region was higher in EC tissues [methylation rate was $68.6 \%(48 / 70)]$ than that in adjacent normal tissues [methylation rate was $21.4 \%(15 / 70)](p<0.05)$ (Fig. 4c). These results suggest that the high methylation level of MTHFR led to reduction of MTHFR expression in EC.

Subsequently, we speculated whether methylation of the MTHFR promoter region was regulated by HOTAIR. In order to analyze the correlation between methylation level of MTHFR promoter region and lncRNA HOTAIR, a Blast comparison was applied to identify possible binding sites between the lncRNA HOTAIR and MTHFR promoter regions. The results showed that there were base complementary binding sites between the IncRNA HOTAIR and MTHFR promoter regions (Fig. 4d). Dual luciferase reporter gene assay displayed that the luciferase activity of MTHFRWT was reduced in the presence of HOTAIR as compared to that of MTHFR-MUT $(p<0.05)$ (Fig. 4e), suggesting that HOTAIR can bind to the promoter region of the MTHFR gene, which was consistent with bioinformatic prediction. Further, RIP was employed to determine the enrichment of HOTAIR in relation to DNA methyltransferases DNMT1, DNMT3a and DNMT3b. The TE-1/5-FU cells overexpressing HOTAIR showed marked enrichment of HOTAIR onto the methyltransferases (Fig. 4f). In addition, CHIP was performed to determine enrichment of methyltransferases within the MTHFR promoter region, which showed that the methyltransferases were remarkably enriched in the MTHFR promoter region in TE-1/5-FU cells overexpressing HOTAIR (Fig. 4g).

In addition, MSP was utilized to assess the methylation level in the CPG site of the MTHFR promoter region in TE-1 cells with restored or depleted HOTAIR. The results indicated that the CpG sites of the MTHFR promoter region had high methylation in TE-1 cells with elevated HOTAIR (Fig. 4h), and MTHFR expression decreased (Fig. 4i-k), whereas the level of methylation was decreased following the downregulation of HOTAIR, (Fig. 4h) along with elevated levels of MTHFR (Fig. 4i-k). To further study the regulating mechanisms of HOTAIR and MTHFR, demethylation of the MTHFR promoter region was conducted using DNA methyltransferase inhibitor 5Aza-CdR. MSP results illustrated that in TE-1 cells treated with overexpressed HOTAIR and DMSO, the MTHFR methylation level was elevated (Fig. 4h), and MTHFR expression decreased (Fig. 4i-k). Upon 5-Aza-CdR addition, the enrichment of the methyltransferases was reduced within the MTHFR promoter region in TE-1 cells (Fig. 4h), and MTHFR expression increased (Fig. 4i-k). The results revealed that the methylation level of the $\mathrm{CpG}$ site within the MTHFR promoter region was closely correlated with the expression of HOTAIR. In sum, the effect of HOTAIR on the methylation level of the MTHFR promoter region was exerted through DNA methyltransferases. 
A

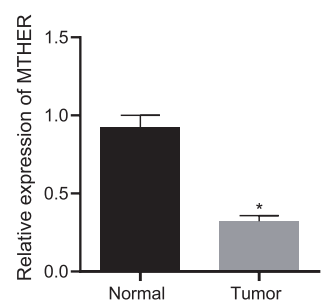

C
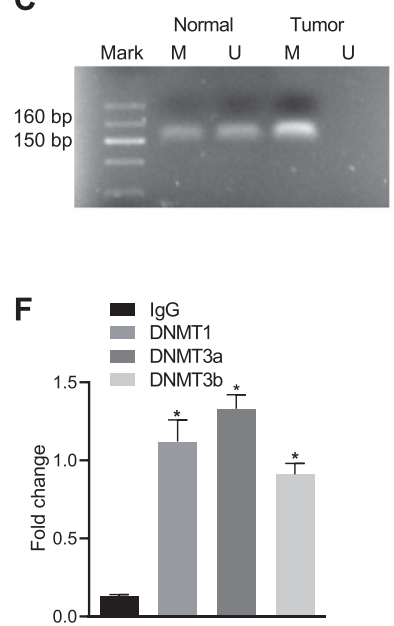

I sh-NC

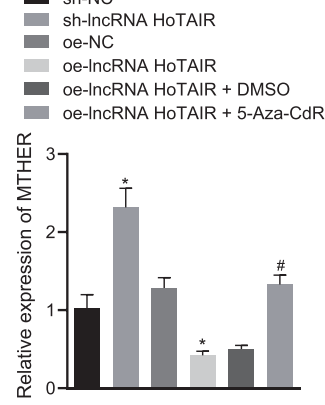

B

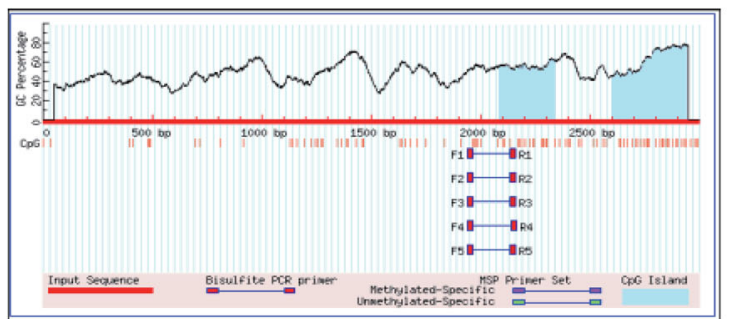

D

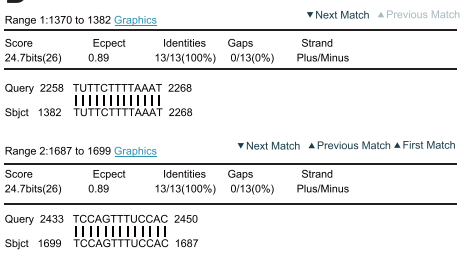

E

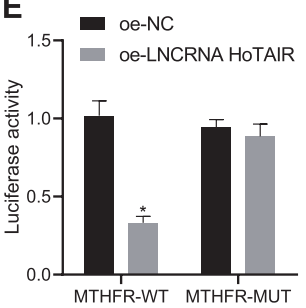

G

- oe-NC

oe-LNCRNA HoTAIR

H

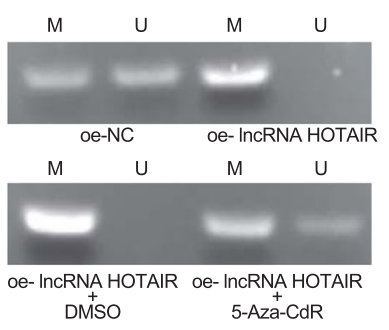

J

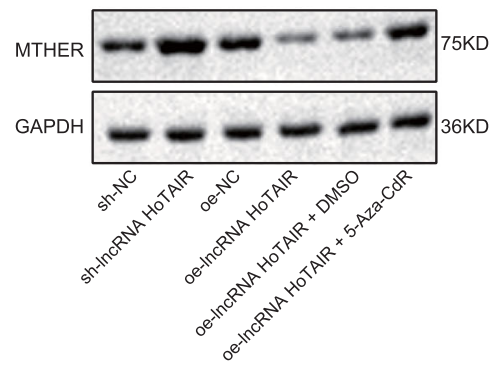

K

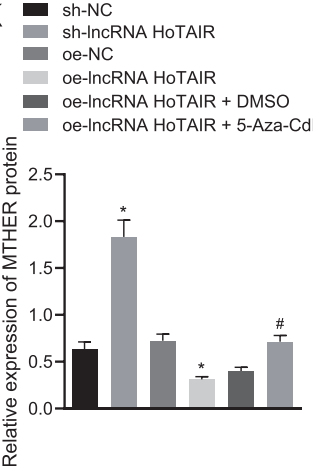

Fig. 4 HOTAIR modulates DNA methylation within MTHFR promoter region. shRNA was delivered into TE-1 cells to specifically blunt HOTAIR (shIncRNA HOTAIR group). Expression vectors containing the IncRNA HOTAIR were introduced into TE-1 cells (oe-IncRNA HOTAIR group). Scramble shRNA-treated cells and empty vectors-treated cells were served as negative controls (sh-NC group and oe-NC group). Moreover, TE-1 cells treated with restored HOTAIR were added with either 5-Aza-CdR or DMSO. (a) MTHFR mRNA level in EC tissues $(n=70)$ and adjacent normal tissues $(n=70)$ determined by RT-qPCR, normalized to GAPDH. (b) Distribution of CpG islands within MTHFR promoter region. (c) MSP was adopted to detect methylation level of MTHFR promoter region in EC tissues $(n=70)$ and adjacent normal tissues $(n=70)$. (d) The binding sites between the IncRNA HOTAIR and MTHFR promoter regions predicted using Blast comparison website. (e) Target relationship verified by dual luciferase reporter gene assay. (f) RIP was utilized to detect the enrichment of DNA methyltransferases (DNMT1, DNMT3a and DNMT3b) affected by HOTAIR in TE-1 cells. (g) CHIP was employed to detect the enrichment of DNA methyltransferases (DNMT1, DNMT3a, and DNMT3b) within MTHFR promoter region in TE-1 cells. (h), MSP was used to detect methylation level of TE-1 cells. (i) MTHFR mRNA level in TE-1 cells after restoration or depletion of HOTAIR determined by RT-qPCR, normalized to GAPDH. MTHFR (75kD), GAPDH (36kD) (j) MTHFR protein level in TE-1 cells after restoration or depletion of HOTAIR determined by Western blot analysis, normalized to GAPDH. (k) Protein band patterns of MTHFR in TE-1 cells after restoration or depletion of HOTAIR determined by Western blot analysis, normalized to GAPDH. Values obtained from three independent experiments in triplicate are expressed as mean \pm SD and analyzed by paired t test between EC tissues and adjacent normal tissues, by unpaired t test between EC cells and HEEC cells, and by ANOVA followed by Tukey's post hoc test among three or more groups. ${ }^{*} p<0.05$ compared with adjacent normal tissues, or TE-1 cells treated with IgG, oe-IncRNA HOTAIR + DMSO, sh-NC, or oe-NC group 
MTHFR facilitated chemosensitivity of EC cells to 5-FU It has been shown that MTHFR was poorly expressed in EC. In order to study the effect of MTHFR on the chemosensitivity of TE-1/5-FU cells to 5-FU, Western blot analysis was performed to measure the MTHFR protein levels in TE-1 cells and TE-1/5-FU cells, which suggested that HOTAIR exhibited a higher expression in TE-1/5-FU cells than in TE-1 cells $(p<0.05)$ (Fig. 5a). Next, TE-1/5-FU cells were treated with elevated MTHFR and/or lncRNA HOTAIR to verify the roles of MTHFR in chemosensitivity of EC cells to 5-FU. Western blot analysis revealed that MTHFR expression increased in TE-1/5-FU cells treated with overexpressed MTHFR, and decreased in TE-1/5-FU cells treated with overexpressed MTHFR and lncRNA HOTAIR (Fig. 5b). In addition, the CCK-8 assay displayed that upregulated MTHFR inhibited cell viability $(p<0.05)$ (Fig. $5 c$ ) and reduced $\mathrm{IC}_{50}$, and the effects of elevated HOTAIR could be reversed by overexpressed MTHFR, which suggested that upregulation of MTHFR promoted the chemosensitivity and inhibited the chemoresistance of TE-1/5-FU cells to 5-FU ( $p<0.05)$ (Fig. 5d). EdU assay and flow cytometry showed that elevated MTHFR suppressed TE-1/ 5 -FU cell proliferation and enhanced apoptosis $(p<0.05)$ (Fig. 5e, f), while the effects of elevated HOTAIR could be reversed by overexpressed MTHFR. Moreover, PI staining and flow cytometry results revealed that overexpression of MTHFR increased the cells at the G0/G1 phase, but reduced the cells in the $S$ phase, indicating that the effects of elevated HOTAIR on EC cell cycle could be reversed by overexpressed MTHFR $(p<0.05)$ (Fig. $5 \mathrm{~g}$ ). These results confirmed that restoration of MTHFR facilitated chemosensitivity to 5-FU and apoptosis while suppressing the proliferation of EC cells.

\section{Silencing of HOTAIR promoted chemosensitivity of EC cells to 5 -FU in vivo}

To further study the regulatory effects of lncRNA HOTAIR on chemosensitivity of EC cells in vivo, TE-1 cells treated with vectors containing sh-NC and shlncRNA HOTAIR, oe-NC, or oe-lncRNA HOTAIR were inoculated into nude mice. Twenty-eight days after TE-1

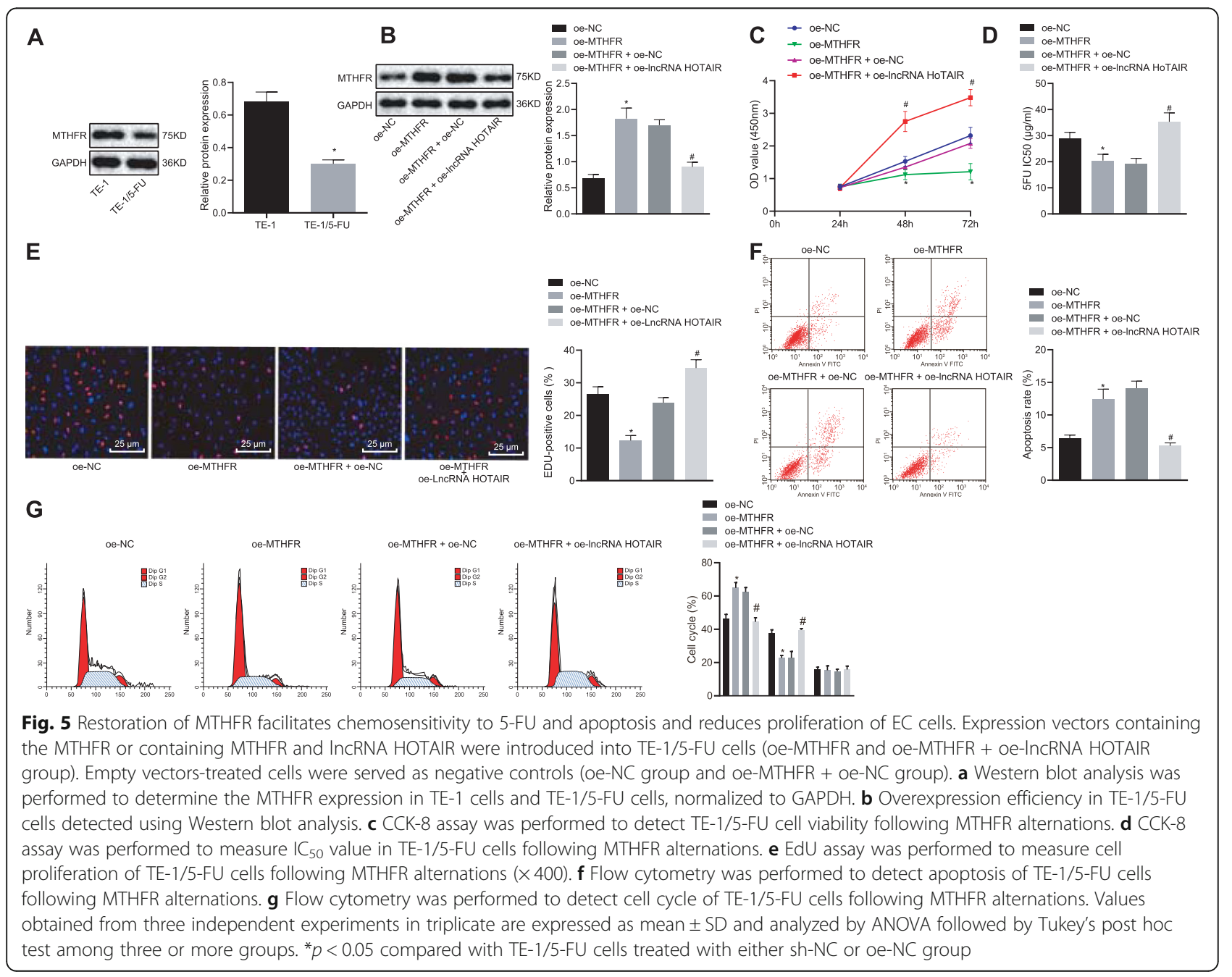


implantation, we examined whether silencing of lncRNA HOTAIR increased the sensitivity of EC cells to 5-FU. When the size of transplanted tumors was larger than $600 \mathrm{~mm}^{3}$, nude mice were intraperitoneally injected with 5-FU and DMSO (as control). The results implied that tumor volume and weight significantly reduced in nude mice injected with cells treated with sh-lncRNA HOTAIR and DMSO, and 5-FU treatment further inhibited tumor growth $(p<0.05)$. However, increased tumor volume and weight were observed in nude mice injected with cells treated with oe-lncRNA HOTAIR and DMSO, whereas no marked difference was identified upon 5-FU treatment (Fig. 6a-f). Immunohistochemistry showed that the positive rate of MTHFR in tumors was significantly increased by silencing of IncRNA HOTAIR $(p<$ 0.05 ), and an opposite trend was observed upon overexpression of lncRNA HOTAIR (Fig. 6g-h). MSP results revealed that silencing of IncRNA HOTAIR inhibited MTHFR methylation in tumor tissues, and an opposite trend was observed upon overexpression of lncRNA HOTAIR (Fig. 6j-k). These findings illustrated that HOTAIR knockdown could upregulate MTHFR to promote chemosensitivity of EC cells to 5-FU in vivo.

\section{Discussion}

EC, affecting more than 450,000 people, remains the sixth leading cause of cancer-related death worldwide [4]. Despite progressive improvements in the arena of chemotherapy of EC, resistance to chemotherapy remains a stumbling block [5]. In recent years, an IncRNA, HOTAIR, has been reported to exert an anticarcinogenic effect on EC [10]. The aim of the present study was to determine the modulatory effects of silencing of HOTAIR on the cellular chemosensitivity of EC in relation to 5-FU mediated via the regulation of MTHFR methylation.

Initially, the data obtained in the present study demonstrated that HOTAIR was upregulated in EC tissues, particularly in EC tissues resistant to 5-FU. Accumulating data have similarly indicated that many lncRNAs are aberrantly expressed in various human cancers, including EC [21]. A number of lncRNAs, including HOTAIR, are reported as highly expressed in EC tissues and cells [7]. The results of the current study displayed that silencing of HOTAIR promoted chemosensitivity to 5-FU and apoptosis while repressing cell proliferation and tumor growth in EC. In general, IncRNAs have been shown to be key mediators in chemoresistance, and lncRNA LINC00261 has been reported to significantly modulate the chemoresistance observed in 5 -FU in human EC [22]. Lu et al. have similarly shown that 5-FU could repress proliferation and induce the apoptosis of EC cells [5]. Interestingly, the depletion of HOTAIR has been noted to inhibit 5-FU resistance in colorectal cancer, suppress cell viability and induce G1-phase arrest of colorectal cancer cells [23]. Overexpression of HOTAIR is associated with the elevation of cell proliferation, migration, and invasion in EC, facilitating its progression and development [9]. Other co-workers have also confirmed that depletion of IncRNA HOTAIR contributes to the inhibition of cell proliferation and tumor metastasis and facilitation of apoptosis in ESCC [8, 24], corresponding with the findings of the present study. Taken together, there exists significant evidence indicating that

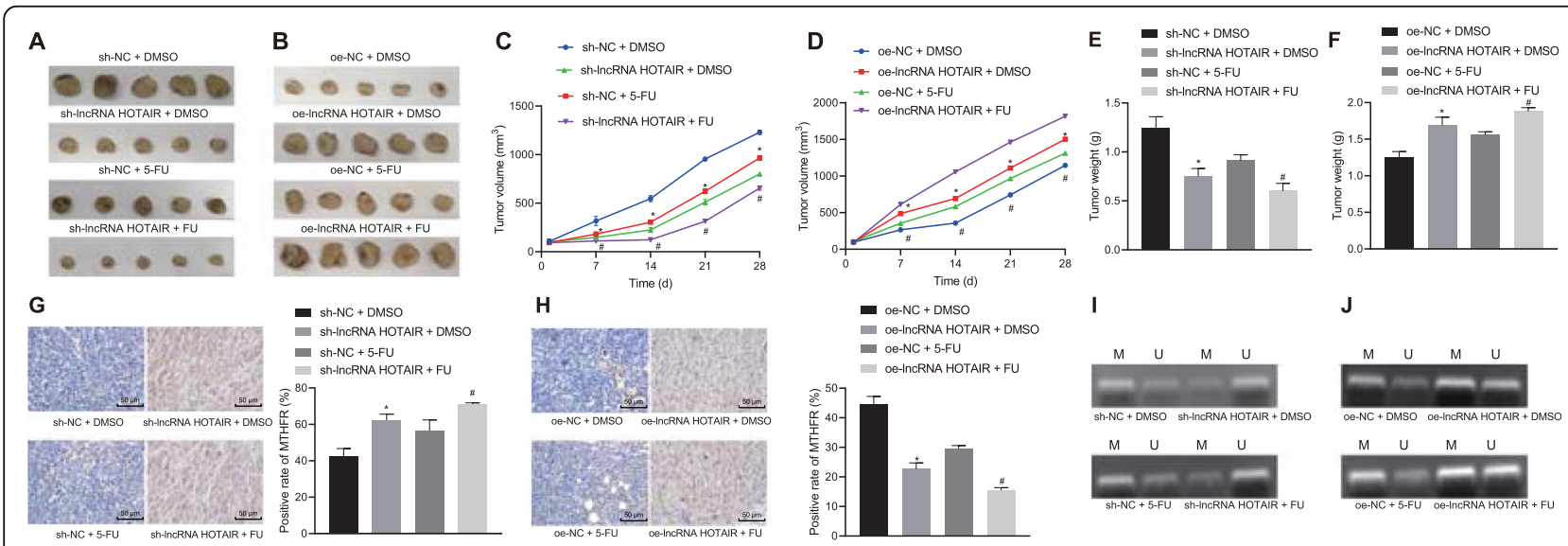

Fig. 6 Silencing of HOTAIR elevates chemosensitivity of EC cells to 5-FU and suppresses tumor growth by elevating MTHFR in vivo. Nude mice were injected with TE-1 cells treated with oe-NC, oe-InCRNA HOTAIR sh-NC and sh-IncRNA HOTAIR vectors, followed by intraperitoneal injection of 5-FU and DMSO $(n=6)$. $\mathbf{a}, \mathbf{b}$ Transplanted tumors of nude mice following treatment. $\mathbf{c}$, $\mathbf{d}$ Tumor volume of nude mice following treatment. $\mathbf{e}, \mathbf{f}$ Tumor weight of nude mice following treatment. $\mathbf{g}$, $\mathbf{h}$ The positive rate of MTHFR expression in transplanted tumors following treatment, measured by Immunohistochemistry (× 200). i, j MTHFR methylation in transplanted tumor tissues following treatment, measured by MSP. Values obtained from three independent experiments in triplicate are expressed as mean \pm SD and analyzed by ANOVA followed by Tukey's post hoc test among three or more groups. ${ }^{*} p<0.05$ compared with TE-1/5-FU cells treated with sh-NC group 


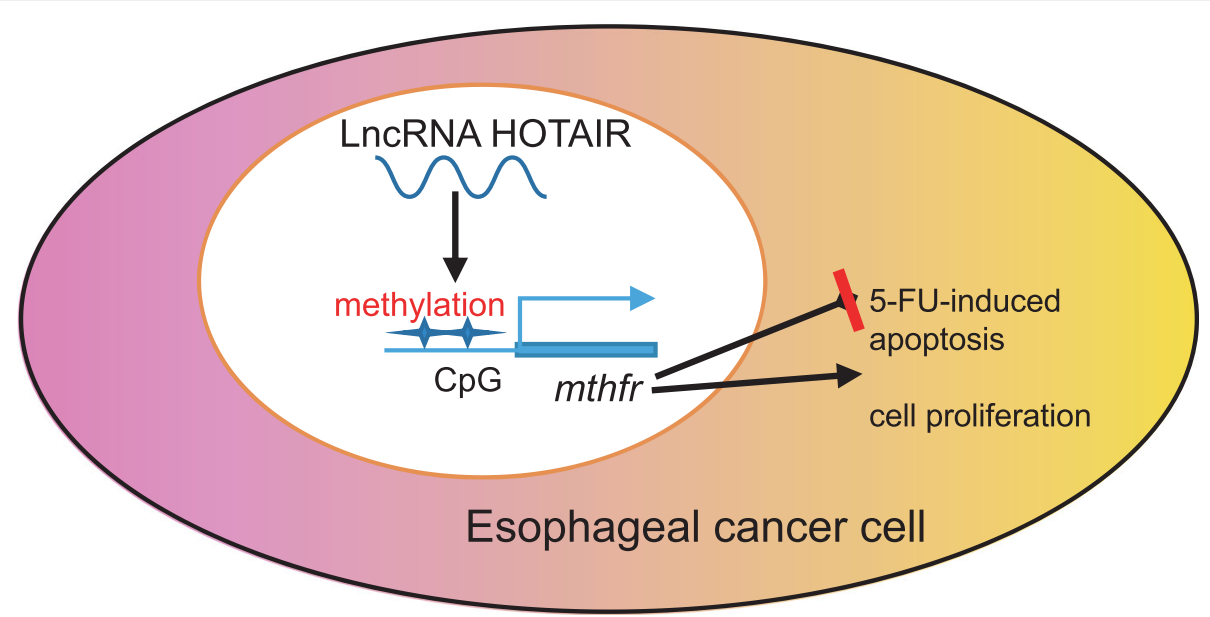

Fig. 7 A schematic representation of the function of IncRNA-HOTAIR in the progression of EC by regulating MTHFR. LncRNA HOTAIR downregulated MTHFR expression via elevating MTHFR methylation, thus contributing to enhanced cell proliferation, but inhibited cell apoptosis and the chemosensitivity of EC cells to 5-FU

HOTAIR is able to promote the chemosensitivity of EC cells to 5-FU by inhibiting proliferation and increasing the apoptosis of EC cells.

The present study also demonstrated that MTHFR was poorly expressed in EC tissues and cells, and elevated MTHFR enhanced chemosensitivity of EC cells to 5-FU with exhibition of lower methylation levels at the MTHFR promoter region. It has been confirmed that MTHFR is of great significance in the progression and development of EC [16]. At present, 5-FU is regarded to be the most common chemotherapeutic treatment option in colorectal cancer, and systemic exposure to 5 -FU is reported as generally regulated by MTHFR [25]. A recent study has demonstrated that MTHFR could induce the sensitivity of colorectal cancer cells to 5-FU [17]. Our results imply that silencing of HOTAIR elevated MTHFR expression by decreasing MTHFR methylation. DNA methylation has been said to exert its influence on the chemosensitivity of cancers by regulating expression of genes associated with cell cycle and apoptosis [26]. The MTHFR is reported to play anti-tumor roles in human cancers through hypomethylation of DNA [27]. HOTAIR is also proved to regulate DNA methylation [14], although the targeting relationship between HOTAIR and MTHFR has not been documented earlier. Based on our findings and existing evidence, we suggest that HOTAIR expression is negatively correlated with MTHFR expression via DNA methylation. Overall, the current study has demonstrated that downregulation of HOTAIR increased MTHFR expression by decreasing MTHFR methylation, leading to an elevation in the chemosensitivity of EC cells to 5-FU.

\section{Conclusion}

In conclusion, silencing of lncRNA HOTAIR promotes the chemosensitivity of EC cells to 5-FU and leads to abnormal cell proliferation and apoptosis of EC cells via the regulation of MTHFR methylation (Fig. 7). This identification of HOTAIR knockdown via MTHFR in mediating the chemosensitivity of EC cells to 5-FU may advance an understanding of the molecular mechanisms underpinning EC, with the potential of serving as a prognostic marker during chemotherapeutic treatment of EC. Moreover, our results provided a novel glimpse of the mechanistic link between essential non-coding RNA HOTAIR and MTHFR, and proposed the negative regulatory axis between HOTAIR/MTHFR as a promising molecular target for EC intervention. Further studies are required, however, to fully understand the specific mechanisms of HOTAIR combined with MTHFR methylation on chemosensitivity to 5-FU treatment in EC.

\section{Abbreviations}

EC: Esophageal cancer; 5-FU: 5-fluorouracil; IncRNAs: long non-coding RNAs; DNMTs: DNA methyltransferases; MTHFR: Methylenetetrahydrofolate reductase; HOTAIR: HOX transcript antisense RNA

\section{Acknowledgements}

We express our sincere gratitude to our colleagues for their suggestions and assistance.

\section{Authors' contributions \\ Shuyao Zhang, Liqun Zhang, Zuojun Huang, Zhen Pan and Qiuzhen Zhang participated in designing the experiments, performed most of the experiments and wrote the manuscript. Fuchun Zheng, Chenchen $\mathrm{Xu}$, Yi Jiang and Shuyi Gu contributed to various experiments. Xiaoshan Huang, Shuang Chen, Chengkuan Zhao and Ganggang Shi conceived and designed the experiments and oversaw all aspects of the study. All authors had final approval of the submitted and published versions.}

\section{Funding}

This study was supported by the Letter from the Third Batch and Fourth Batch of Medical and Health Science and Technology Program Project Funds in Shantou City in 2018 [Shan Fu Ke letter (2018) 238] and Dedicated Fund for Tumor-Targeting of Wu Jieping Medical Foundation (Project ID: 320.6750.19090-2). 


\section{Availability of data and materials}

The datasets generated and/or analysed during the current study are available from the corresponding author upon reasonable request.

\section{Ethics approval and consent to participate}

The study protocol was approved by the Ethics Committee of the Cancer Hospital of Shantou University Medical College. Written informed consent was obtained from all patients prior to enrollment. All animal experiments were conducted in accordance with the Guide for the Care and Use of Laboratory Animal by International Committees. Every effort was made to minimize the numbers and suffering of the included animals.

\section{Consent for publication}

Not applicable.

\section{Competing interests}

The author declares no competing interest exists.

\section{Author details}

'Department of Pharmacology, Shantou University Medical College, Shantou 515041, P.R. China. ${ }^{2}$ Department of Pharmacology, Guangzhou Red Cross Hospital, Jinan University, Guangzhou 510220, P.R. China. ${ }^{3}$ Pharmaceutical Laboratory, The First Affiliated Hospital, Shantou University Medical College, Shantou 515041, P.R. China. ${ }^{4}$ Information Section, Cancer Hospital of Shantou University Medical College, Shantou 515031, P.R. China. ${ }^{5}$ Department of Digestive Oncology, Cancer Hospital of Shantou University Medical College, Shantou 515031, P.R. China.

\section{Received: 29 December 2019 Accepted: 29 May 2020}

Published online: 11 July 2020

\section{References}

1. Li B, Xu WW, Han L, Chan KT, Tsao SW, Lee NPY, et al. MicroRNA-377 suppresses initiation and progression of esophageal cancer by inhibiting CD133 and VEGF. Oncogene. 2017;36(28):3986-4000.

2. Hu Y, Correa AM, Hoque A, Guan B, Ye F, Huang J, et al. Prognostic significance of differentially expressed mirnas in esophageal cancer. Int J Cancer. 2011;128(1):132-43.

3. Liu J, Wang Z, Wu K, Li J, Chen W, Shen Y, et al. Paclitaxel or 5-fluorouracil/ esophageal stent combinations as a novel approach for the treatment of esophageal cancer. Biomaterials. 2015;53:592-9.

4. Lin EW, Karakasheva TA, Hicks PD, Bass AJ, Rustgi AK. The tumor microenvironment in esophageal cancer. Oncogene. 2016;35(41):5337-49.

5. Chuang-Xin L, Wen-Yu W, Yao C, Xiao-Yan L, Yun Z. Quercetin enhances the effects of 5-fluorouracil-mediated growth inhibition and apoptosis of esophageal cancer cells by inhibiting nf-kappab. Oncol Lett. 2012;4(4):775-8.

6. Jin YY, Chen QJ, Xu K, Ren HT, Bao X, Ma YN, et al. Involvement of microrna-141-3p in 5-fluorouracil and oxaliplatin chemo-resistance in esophageal cancer cells via regulation of pten. Mol Cell Biochem. 2016; 422(1-2):161-70

7. Liang Y, Chen X, Wu Y, Li J, Zhang S, Wang K, et al. Lncrna casc9 promotes esophageal squamous cell carcinoma metastasis through upregulating lamc2 expression by interacting with the creb-binding protein. Cell Death Differ. 2018;25(11):1980-95

8. Lv XB, Lian GY, Wang HR, Song E, Yao H, Wang MH. Long noncoding rna hotair is a prognostic marker for esophageal squamous cell carcinoma progression and survival. PLoS One. 2013;8(5):e63516.

9. Xu F, Zhang J. Long non-coding rna hotair functions as mirna sponge to promote the epithelial to mesenchymal transition in esophageal cancer. Biomed Pharmacother. 2017;90:888-96.

10. Chen FJ, Sun M, Li SQ, Wu QQ, Ji L, Liu ZL, et al. Upregulation of the long non-coding rna hotair promotes esophageal squamous cell carcinoma metastasis and poor prognosis. Mol Carcinog. 2013;52(11):908-15.

11. Yan J, Dang Y, Liu S, Zhang Y, Zhang G. Lncrna hotair promotes cisplatin resistance in gastric cancer by targeting mir-126 to activate the pi3k/akt/ mrp1 genes. Tumour Biol. 2016;37(12):16345-55.

12. Reinert T, Modin C, Castano FM, Lamy P, Wojdacz TK, Hansen LL, et al. Comprehensive genome methylation analysis in bladder cancer: identification and validation of novel methylated genes and application of these as urinary tumor markers. Clin Cancer Res. 2011;17(17):5582-92.
13. Huang FL, Yu SJ. Esophageal cancer: risk factors, genetic association, and treatment. Asian J Surg. 2018;41(3):210-5

14. Cheng D, Deng J, Zhang B, He X, Meng Z, Li G, et al. Lncrna hotair epigenetically suppresses mir-122 expression in hepatocellular carcinoma via DNA methylation. EBioMedicine. 2018;36:159-70.

15. Tserga A, Binder AM, Michels KB. Impact of folic acid intake during pregnancy on genomic imprinting of igf2/h19 and 1-carbon metabolism. FASEB J. 2017;31(12):5149-58.

16. Tang W, Zhang S, Qiu H, Wang L, Sun B, Yin J, et al. Genetic variations in mthfr and esophageal squamous cell carcinoma susceptibility in chinese han population. Med Oncol. 2014;31(5):915.

17. Pardini B, Kumar R, Naccarati A, Novotny J, Prasad RB, Forsti A, et al. 5fluorouracil-based chemotherapy for colorectal cancer and mthfr/mtrr genotypes. Br J Clin Pharmacol. 2011;72(1):162-3.

18. Lebeau A, Kriegsmann M, Burandt E, Sinn HP. Invasive breast cancer: the current who classification. Pathologe. 2014;35(1):7-17.

19. Kwan ML, Haque R, Lee VS, Joanie Chung WL, Avila CC, Clancy HA, et al. Validation of ajcc tnm staging for breast tumors diagnosed before 2004 in cancer registries. Cancer Causes Control. 2012;23(9):1587-91.

20. Lee JJ, Geli J, Larsson C, Wallin G, Karimi M, Zedenius J, et al. Gene-specific promoter hypermethylation without global hypomethylation in follicular thyroid cancer. Int J Oncol. 2008;33(4):861-9.

21. Pan Z, Mao W, Bao Y, Zhang M, Su X, Xu X. The long noncoding rna casc9 regulates migration and invasion in esophageal cancer. Cancer Med. 2016; 5(9):2442-7.

22. Lin K, Jiang H, Zhuang SS, Qin YS, Qiu GD, She YQ, et al. Long noncoding rna linc00261 induces chemosensitization to 5 -fluorouracil by mediating methylation-dependent repression of dpyd in human esophageal cancer. FASEB J. 2019;33(2):1972-88.

23. Li P, Zhang $X$, Wang L, Du L, Yang Y, Liu T, et al. Lncrna hotair contributes to 5 fu resistance through suppressing mir-218 and activating nf-kappab/ts signaling in colorectal cancer. Mol Ther Nucleic Acids. 2017;8:356-69.

24. Li X, Wu Z, Mei Q, Li X, Guo M, Fu X, et al. Long non-coding rna hotair, a driver of malignancy, predicts negative prognosis and exhibits oncogenic activity in oesophageal squamous cell carcinoma. Br J Cancer. 2013;109(8): 2266-78.

25. Nahid NA, Apu MNH, Islam MR, Shabnaz S, Chowdhury SM, Ahmed MU, et al. Dpyd*2a and mthfr c677t predict toxicity and efficacy, respectively, in patients on chemotherapy with 5 -fluorouracil for colorectal cancer. Cancer Chemother Pharmacol. 2018;81(1):119-29.

26. Suzuki M, Shinohara F, Nishimura K, Echigo S, Rikiishi H. Epigenetic regulation of chemosensitivity to 5 -fluorouracil and cisplatin by zebularine in oral squamous cell carcinoma. Int J Oncol. 2007;31(6):1449-56.

27. Tan X, Wang YY, Dai L, Liao XQ, Chen MW. Genetic polymorphism of mthfr a1298c and esophageal cancer susceptibility: a meta-analysis. Asian Pac J Cancer Prev. 2013;14(3):1951-5.

\section{Publisher's Note}

Springer Nature remains neutral with regard to jurisdictional claims in published maps and institutional affiliations.

Ready to submit your research? Choose BMC and benefit from:

- fast, convenient online submission

- thorough peer review by experienced researchers in your field

- rapid publication on acceptance

- support for research data, including large and complex data types

- gold Open Access which fosters wider collaboration and increased citations

- maximum visibility for your research: over $100 \mathrm{M}$ website views per year

At BMC, research is always in progress.

Learn more biomedcentral.com/submissions 